\title{
Microsimulation of the Firm and the Economy
}

\author{
F. W. van Tongeren \\ Erasmus University Rotterdam, \\ The Netherlands
}

The article presents a microsimulation model of firm behavior in an economy-wide setting. A combination of microsimulation and general equilibrium modelling approaches is proposed as an alternative research method to incorporate typical industrial organization issues into economy-wide modelling. The article centers around an application that uses Dutch firms and the Dutch economy as case studies.

KEYWORDS: applied general equilibrium; corporate simulation; microsimulation; industrial organization; industrial policy.

This article puts forward a microsimulation (MS) approach that models individual firms and integrates them into an economy-wide framework. With business economics, it shares the view that individual cases are important and differences between firms should fully be recognized. However, the model goes a step further and integrates specific cases and individual firms into a general system of economic relations. The model provides a meeting ground for business economics, industrial organization, general economic modelling and accounting statistics. The model has been designed to serve as a vehicle for research and theory construction. See Greenblat (1975) for a discussion of simulation as a tool in theory development. In terms of economic research, the model's main areas of application are

- the analysis of sector- and economy-wide implications of developments at the firm level, and

- the analysis of the impact of changes at the macrolevel on the microlevel and feedback to the aggregate.

AUTHOR'S NOTE: Financial support by the Dutch Organization for Scientific Research (NWO) is gratefully acknowledged.

SIMULATION \& GAMING, Vol. 28 No. 2, June 1997 225-229

Cㅇ 1997 Sage Publications, Inc. 
Further, it promises fruitful applications as tools in corporate planning and, somewhat related, as a core for the development of management simulation games. The economy-wide specification distinguishes it from most computerized management simulation games (see, e.g., the applications reviewed in Dickinson \& Faria, 1995).

\section{MS Modelling}

Many applications of MS modelling in areas like social security, housing policy, and income-tax reforms have shown the usefulness of this approach (see Merz, 1991; Orcutt, Merz, \& Quinke, 1986; and Sutherland, 1995, for surveys of MS models in Europe and the United States). Most applications concern the household sector, whereas MS of firms is a relatively less developed area. Our model has many common elements with a well-developed Swedish simulation model of firm behavior (see Eliasson, 1985).

Successful application of MS models has primarily been achieved in areas where indirect—or induced—effects are negligible and the primary concerns are distribution effects. The drawback of this partial approach is obviously that its validity is confined to situations in which the impulses are small enough to safely assume no drastic behavioral changes at the microlevel.

Many practical policy problems will deal with circumstances where a change in economic conditions will trigger behavioral reactions that in turn will affect the economy at large. Such feedback mechanisms are fully captured in our MS model.

\section{Model Overview}

Our MS model explicitly allows for differences in technology, motivation, and behavior of the simulated firms. Firms operate on imperfectly competitive markets with differentiated products. Firms are not perfectly informed about the market conditions, but learn from past mistakes and gradually adjust their behavior. Firm behavior is modelled by deterministic simulation of decision processes. The basic time unit of the model is 1 year.

Our modelling of firm behavior is based on a distinction between routine behavior and long-run decisions. Routine decisions are based on established rules for problem solving. Instead of searching for globally optimal solutions, the firm uses established routines to determine its short-run reactions to short-run problems (see Carvalho, 1991, for a discussion of the use of behavioral decision algorithms in computerized simulations). 
The accounting framework forms the basis for monitoring the current state and development of future plans. The model maintains three interrelated sets of accounts: a profit/loss account, a balance sheet, and a cash flow account.

An accelerator mechanism triggers the firm's search for investment alternatives, which are available in discrete technological packages with specific production possibilities. The profitability assessment uses an integrated forecast of the firm's accounts to estimate its state with and without new investment. In its financing decision, the firm follows the so-called "pecking order" approach for alternative sources of finance: retained profits, debt financing, and the emission of new shares.

As in applied general equilibrium models, the fundamental notion of modelling interdependent markets is fully incorporated by embedding the firm in an extended input-output structure covering the entire economy. The MS model has a corresponding aggregate accounting representation in the form of a social accounting matrix, which monitors the endogenously generated circular flow of income and expenditures.

\section{Implementation: The Case of Dutch Firms}

The model has been calibrated to data for The Netherlands for the period 1978 to 1987, using microdata on a selection of firms in conjunction with published sectoral data from statistical agencies. The bulk of the calibration work took place at the microlevel where some 350 parameters had to be estimated.

The current implementation features a selection of 10 Dutch corporations in four manufacturing sectors: 4 firms in food and beverage industries, 4 firms in chemical industries, $1 \mathrm{firm}$ in basic metal, and $1 \mathrm{firm}$ in the electrotechnical industry. Only those four sectors are popu- lated by microsimulated firms; other manufacturing and nonmanufacturing industries are treated differently and are aggregated into eight nonmicrosimulated sectors. On average, the microsimulated firms represent more than $50 \%$ of value added in their sectors.

Simulation results are scaled to aggregate totals by using scaling weights for microsimulated firms in conjunction with a "residual firm" that is intended to reflect the behavior of small- and medium-sized firms in the sector.

The calibration procedure results in a base-run simulation for the period 1978 to 1987, which serves as a reference for experimental runs. The model has been used for three types of experiments in van Tongeren (1995) to clarify how this alternative model differs in its operation and results from received theoretical and policy analyses. 
The first set of experiments shows that the impact of one single corporate firm on the entire sector, let alone its impact on macroeconomic variables, is limited by economy-wide interdependence. A unilateral action may not yield the desired result for the firm.

The second simulation exercise studies the effects of investment subsidies. The MS model yields rich insights into the mechanisms behind the response to the policy change and yields direct microlevel estimates of profitability and liquidity effects of the subsidy. Such insight cannot be offered by exclusively partial or aggregate approaches.

The third simulation experiment analyzes structural changes at the sectoral level by simulating changes in the size distribution through entry of new firms.

\section{Concluding Remarks}

MS modeling is an alternative method to integrate elements from partial theories (which are characteristic of the industrial organization literature) and economy-wide approaches (such as applied general equilibrium models).

Its flexibility and ability to incorporate institutional details at the microlevel and simulating feedbacks to the macrolevel render MS a fruitful tool for industrial policy assessment as well as for assessment of alternative behavioral specifications. Applications in the area of corporate planning seem very promising, because our MS model goes further than traditional corporate simulation models by endogenizing the demand side and endogenizing competitor's behavior at the supply side. Further, the model could serve as a core for developing an educational version to help students in business and economics understand micro-macro linkages.

\section{References}

Carvalho, G. F. (1991). Evaluating computerized business simulators for objective learning validity. Simulation \& Gaming: An International Journal, 22, 328-347.

Dickinson, J. R., \& Faria, A. J. (1995). Simulation gaming for sales management training and demonstration. In D. Saunders (Ed.), The simulation and gaming yearbook, volume 3: Games and simulation for business (pp. 99-108). London: Kogan Page.

Eliasson, G. (1985). The firm and financial markets in the Swedish micro-to-macro model: Theory, model and verification. Stockholm, Sweden: Almquist \& Wicksell.

Greenblat, C. S. (1975). Gaming-simulation as a tool for social research. In C. S. Greenblat \& R. D. Duke (Eds.), Gaming-simulation: Rationale, design and applications (pp. 320-323). New York: John Wiley.

Merz, J. (1991). Microsimulation: A survey of principles, developments and applications. International Journal of Forecasting, 7, 77-104. 
Orcutt, G. J., Merz, J., \& Quinke, H. (Eds.). (1986). Microanalytic simulation models to support social and financial policy. Amsterdam, The Netherlands: North Holland.

Sutherland, H. (1995). Static microsimulation model in Europe: A survey (DAK Working Paper No. 9523). Cambridge, UK: University of Cambridge, Microsimulation Unit.

Tongeren, F. W. van. (1995). Microsimulation modelling of the corporate firm: Exploring micro-macro economic relations. Berlin: Springer Verlag.

F. W. van Tongeren is an assistant professor in microeconomics at Erasmus University Rotterdam. His research interest lies in the field of industrial organization and simulation modelling. He holds a position as senior economist at the Agricultural Economics Research Institute (LEI-DLO), the Hague, where he is currently working on a microsimulation model for the Dutch agri-food industries.

ADDRESS: F. W. van Tongeren, Erasmus University Rotterdam, Faculty of Economics, H9-12, P.O. Box 1738, 3000 DR Rotterdam, The Netherlands; telephones +31-10-4081863 (w); +31-10-467-8762 (h); fax+31-10-212-1724; e-mail tongeren@micro. few.eur.nl. 